\title{
Statistical Testing of Milled Objects on Numerically Controlled Three-Axis Milling Machines
}

\author{
Paweł Piórkowski ${ }^{1 *}$, Wacław Skoczyński \\ 1 Wrocław University of Science and Technology, Wybrzeże Wyspiańskiego 27, 50-370 Wrocław, Poland \\ * Corresponding author's email: pawel.piorkowski@pwr.edu.pl
}

\begin{abstract}
Statistical studies of the surface distribution of milled workpieces and the possibility of their use for operationbased tests and machine tool evaluation were presented. In the first part of the paper, the assumptions and scope of statistical research were defined and the method of obtaining data on machined surfaces directly from machining programs was described. In the following part of the article, the results of the research consisting in determining the probability of machining operations in the working space of a numerically controlled milling machine were presented on the example of machining programs designed for implementation on the DMC 1035V Ecoline vertical machining centre. The knowledge of the load distribution in the working space of a milling machine associated with the machining process can be used to design and manufacture the test pieces reflecting the machining tasks performed on the milling machine and to develop appropriate acceptance and evaluation procedures.
\end{abstract}

Keywords: milling, milling machines, statistical research on milling, property evaluation

\section{INTRODUCTION}

Work-based tests constitute a group of indirect research, which takes place while a machine tool performs specific technological tasks. The conditions under which the measurements are performed correspond to the actual working conditions, most frequently occurring during the finishing process [1]. The recommendations relating to operation-based studies are also partially standardised [2]. The rules for machining tests depend strictly on the kind, power, type and size of the machine tool. The performance of the operation-based test is usually based on carrying out a number of machining operations on the tested machine tool using test pieces (Figure 1)

The current operation-based test procedures have one thing in common, which is that they are largely based on the subjectively accepted machine user recommendations and individual arrangements between the machine manufacturer and its customer. There are numerous works [5-8], concerning the operation-based research of machine tools, in which the probability distribution of machining operations in the working space of the tested machine tool is not taken into account and is not developed. The reason for this is the lack of appropriate distributions, the development of which requires the knowledge of the spectrum of workpieces. In this publication, an attempt was made to develop such a distribution for the DMC $1035 \mathrm{~V}$ Ecoline vertical machining centre operating under industrial conditions.

\section{Developing applications for discretization of tool positions in the milling machine workspace}

The most difficult task when creating an application for the discretization of the tool positions in the workspace of the milling machine was to establish a compromise between the degree of program complexity and the resulting application complexity and the number of achievable machining programs that will allow the analysis of the loads occurring in the workspace of the machine. It was finally decided to adopt the following simplifying assumptions: 
a)

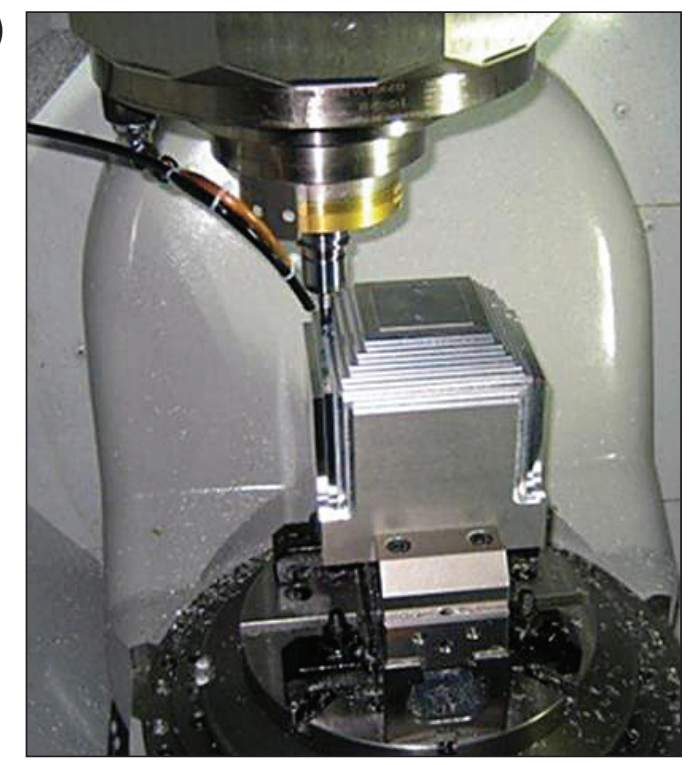

b)

Fig. 1. Examples of test subjects used in operation-based tests: a) on the machining centre [3], b) on a numerically controlled lathe [4]

- The selected programs will concern the processing of flat workpieces machining on numerically controlled three-axis milling machines or such that were performed on other machine tools, but could also be performed on numerically controlled three-axis milling machines,

- The result of the application will be a set of points in the Cartesian system (x, y, z), defining the position of the tool during the execution of subsequent machining operations, determined with an appropriate discretization step,

- The discretisation step will be determined by distance and not by time, so that it is not necessary to analyse the cutting parameters,

- When determining the coordinates of the tool position, fast movements will not be taken into account, but only those that indicate the working movements of the tool,

- The only working movements that may occur in the analyzed program are straight and circular movements.
In the case of the attempts to develop G-code converters, the difficulty in determining the intermediate points during circular movement is primarily indicated, taking into account the discretisation step. In the literature [9] one can find the formulas that allow calculating the coordinates of such points. Ultimately, however, a new proprietary algorithm was used, which also took into account the possibility of introducing an appropriate discretisation step [10]. The idea of the application for discretization of tool positions in the machine working space is illustrated in Figure 2.

Finally, assuming an appropriate discretization step, the effect of the program is to obtain all the discretized tool position coordinates in the milling machine workspace. The application used for this purpose allows the necessary information to be obtained from the machining program to determine the load distribution occurring in the machine working space during machining. The algorithm for determining the coordinates of the

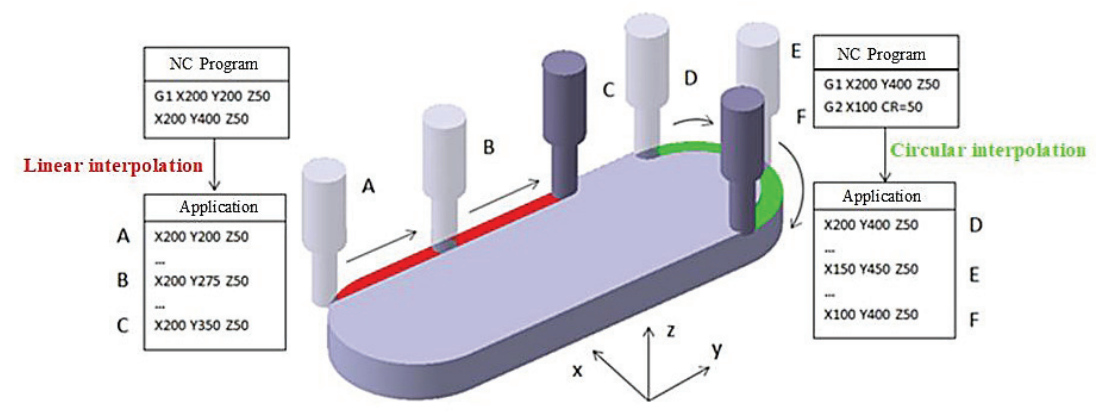

Fig. 2. The idea of the application for determining the position distribution of the machined surfaces on milled workpieces 
tool position in the working space of the numerically controlled milling machine is performed according to the adopted block diagram (Figure 3).

\section{Determination of the probability distribution of the tool position in the working space of a numerically controlled milling machine}

The set of all discretized coordinates of the tool's position in the working space made it possible to determine the frequency distribution of events, which was difficult to present in threedimensional space. Therefore, it was decided to simplify the description of this distribution and to present it in the form of many two-dimensional distributions determined for all subranges of nominal dimensions that occur in the working space of the analyzed milling machine. It was established that the most representative statistical distribution that will allow mapping the position of the tool in a single subrange of the machine working space is a two-dimensional Beta distribution. It is a continuous probability distribution, which allows describing it by means of a density function defined on a standardized range $[0,1]$. The function of density of such decomposition takes the following form [11]:

$$
\begin{gathered}
f_{x, y}(x, y)=\frac{\Gamma(\alpha+\beta+\gamma)}{\Gamma(\alpha)+\Gamma(\beta)+\Gamma(\gamma)} . \\
\cdot x^{\alpha-1} \cdot y^{\beta-1} \cdot(1-x-y)^{\gamma-1}
\end{gathered}
$$

According to equation (1), determine the unknown values of $x, y, \boldsymbol{\alpha}, \boldsymbol{\beta}, \boldsymbol{\gamma}$ and determine the values of the unknowns in the form of the Euler's gamma. Eulerss Gamma is a special function that generalizes the notion of factorial to a set of complex and real numbers. Since in the basic formula of the density function of the two-dimensional beta distribution, normalized variables $x$ and $y$ appear, it was established that instead of marking $[x, y]$ coordinate in the working space of the machine tool, the notation $[a, b]$ will be used in the following formulas, so that no collision of markings appears. Accordingly, the normalized values of $x_{i}$ and $y_{i}$ as a function of the density of the two-dimensional beta distribution take the following values:

$$
\begin{aligned}
& x_{i}=\frac{1}{2} \cdot \frac{a_{i}-a_{\min }}{a_{\max }-a_{\min }} \\
& y_{i}=\frac{1}{2} \cdot \frac{b_{i}-b_{\min }}{b_{\max }-b_{\min }}
\end{aligned}
$$

where: $\left[a_{i}, b_{i}\right]$ denote the coordinate of a single point resulting from the discretization of the tool

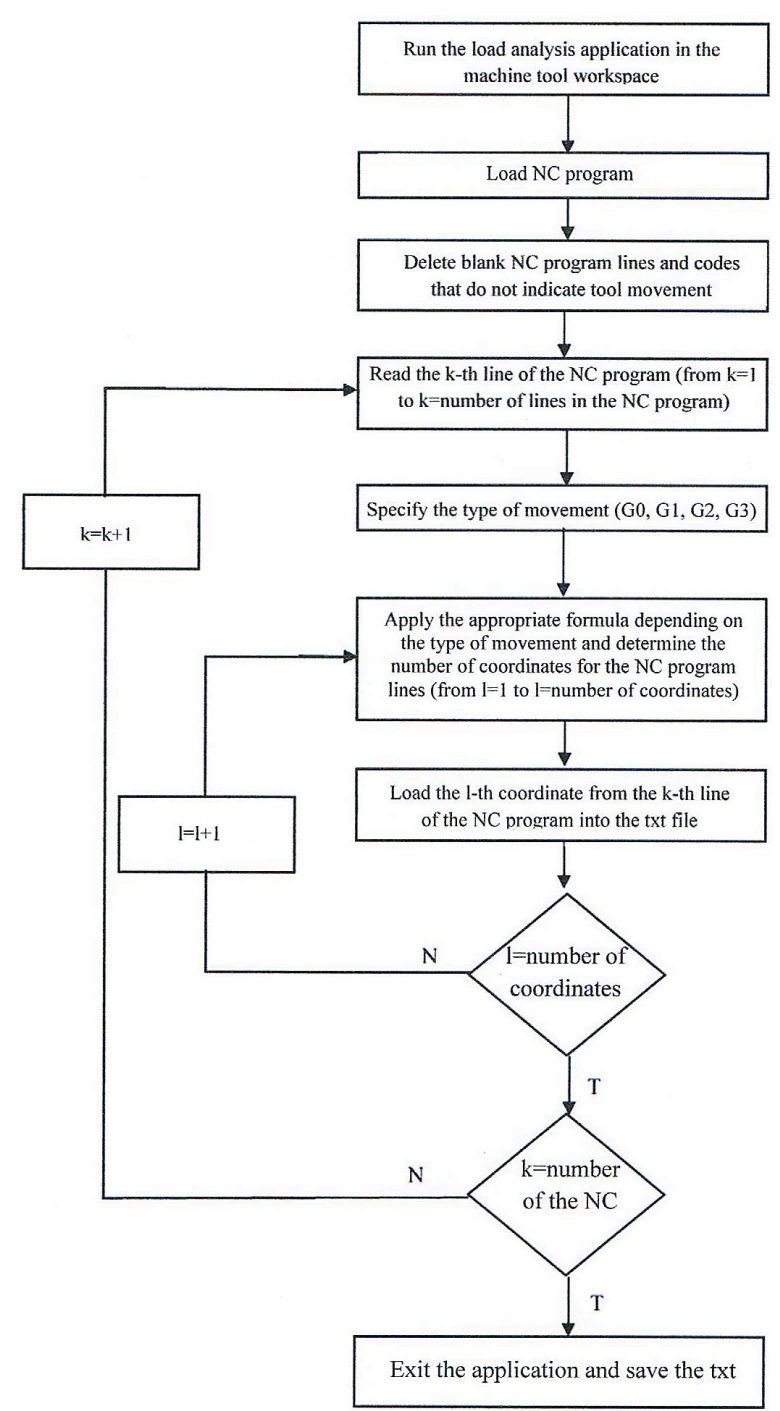

Fig. 3. Algorithm for determining the tool coordinates in the machine's working space

path, a $\left(a_{\text {min }}, a_{\text {max }}\right)$ and $\left(b_{\text {min }}, b_{\text {max }}\right)$ are the values resulting from the size of the machine tool working space, for which a two-dimensional Beta distribution is created.

The values of the $\boldsymbol{\alpha}, \boldsymbol{\beta}, \boldsymbol{\gamma}$ Beta distribution parameters, necessary to determine the distribution density function and to determine the Euler gamma values, take the following form:

$$
\begin{gathered}
\alpha=\beta \cdot \frac{\bar{x}}{\bar{y}} \\
\beta=\frac{\bar{x} \cdot \bar{y}^{2}}{\rho_{x, y} \cdot S_{x} \cdot S_{y}}-\bar{y} \\
\gamma=\frac{\beta}{\bar{y}}-\alpha-\beta
\end{gathered}
$$

In order to determine the values from formulas (4-5) it is necessary to determine the mean values $(\bar{x}, \bar{y})$ and standard deviations $\left(S_{x}, S_{y}\right)$ 
parameters $x$ and $y$, as well as the correlation coefficient between them $\left(\rho_{x, y}\right)$. The following formulas are used for this:

$$
\begin{gathered}
\bar{x}=\frac{1}{2} \cdot \frac{\bar{a}-a_{\min }}{a_{\max }-a_{\min }} \\
\bar{y}=\frac{1}{2} \cdot \frac{\bar{b}-b_{\min }}{b_{\max }-b_{\min }} \\
S_{x}^{2}=\frac{S_{a}^{2}}{4 \cdot\left(a_{\max }-a_{\min }\right)^{2}} \\
S_{y}^{2}=\frac{S_{b}^{2}}{4 \cdot\left(b_{\max }-b_{\min }\right)^{2}} \\
\rho_{x, y}=\frac{\sum\left(x_{i}-\bar{x}\right)\left(y_{i}-\bar{y}\right)}{\sqrt{\sum\left(x_{i}-\bar{x}\right)^{2} \sum\left(y_{i}-\bar{y}\right)^{2}}}
\end{gathered}
$$

The last unknowns in the density function of the two-dimensional Beta distribution remain the Euler gammas, which are determined from the following formulas:

$$
\begin{gathered}
\Gamma(\alpha)=\int_{0}^{\infty} x^{\alpha-1} \cdot e^{-x} d x \\
\Gamma(\beta)=\int_{0}^{\infty} x^{\beta-1} \cdot e^{-x} d x \\
\Gamma(\gamma)=\int_{0}^{\infty} x^{\gamma-1} \cdot e^{-x} d x \\
\Gamma(\alpha+\beta+\gamma)=\int_{0}^{\infty} x^{\alpha+\beta+\gamma-1} \cdot e^{-x} d x
\end{gathered}
$$

These dimensions for the preselected DMC $1035 \mathrm{~V}$ Ecoline vertical machining centre are $1035 \times 560 \times 510 \mathrm{~mm}$. As the evaluation of properties is strongly correlated with acceptable dimensional deviations and related dimensional ranges and ISO accuracy classes, the division into subspaces of the machine tool working space along the z-axis will result from the ranges of nominal dimensions given in ISO tables [12]. Taking into account the assumptions above, the working space of the machine tool has been divided into subspaces in such a way (Figure 4) that:

- The working space of the machine tool along the $x$ axis has been divided into 5 parts (every $207 \mathrm{~mm}$ ),

- The working space of the machine tool along the $y$ axis has been divided into 4 parts (every $140 \mathrm{~mm}$ ),

- The working space of the machine tool along the $z$ axis has been divided into 14 parts (further dimensional ranges are $[\mathrm{mm}]: 0-3,3-6$, 6-10, 10-18, 18-30, 30-50, 50-80, 80-120, $120-180,180-250,250-315,315-400,400-$ 500, 500-510).

For such a division of the working space of the analyzed milling machine (total of 280 subspaces), a highly uneven distribution of machining operations in individual subspaces was obtained. The machine tool system was linked with the workpiece system, based on the data from the industrial sector regarding the tested machine and the methods of clamping appropriate workpieces on it. The position of the workpiece varied in the small extent within the working space of the machine (it is worth mentioning that there is a risk of errors resulting from a human factor and a work of operators). The highest probabilities of machining events were concentrated in only 8 subspaces (Table 1).

The remaining subspace of the milling machines where the machining took place was represented in less than $5 \%$ of the total share, which means that their share in all machining operations was small and will therefore not be used when assessing the properties of the numerically controlled machine tools. On the basis of analysis results, it can be observed for the given workpiece spectrum that machining is mostly carried out in the nominal dimensions (height) range 18-50 $\mathrm{mm}$. It was found that $85.3 \%$ of all machining

Table 1. Subspaces where the machining operations are most likely to occur

\begin{tabular}{|c|c|c|c|}
\hline $\begin{array}{c}\text { Ranges of nominal dimensions } \\
\text { on the } z \text { axis [mm] }\end{array}$ & $\begin{array}{c}\text { Dimensional ranges } \\
\text { on the } x \text { axis [mm] }\end{array}$ & $\begin{array}{c}\text { Dimensional ranges } \\
\text { on the } y \text { axis [mm] }\end{array}$ & $\begin{array}{c}\text { Probability of frequency } \\
\text { of events [\%] }\end{array}$ \\
\hline $30-50$ & $207-414$ & $140-280$ & 21.51 \\
\hline $30-50$ & $207-414$ & $280-420$ & 11.34 \\
\hline $30-50$ & $414-621$ & $140-280$ & 14.19 \\
\hline $30-50$ & $414-621$ & $280-420$ & 10.06 \\
\hline $18-30$ & $207-414$ & $140-280$ & 10.34 \\
\hline $18-30$ & $207-414$ & $280-420$ & 5.83 \\
\hline $18-30$ & $414-621$ & $140-280$ & 6.91 \\
\hline $18-30$ & $414-621$ & $280-420$ & 5.12 \\
\hline
\end{tabular}




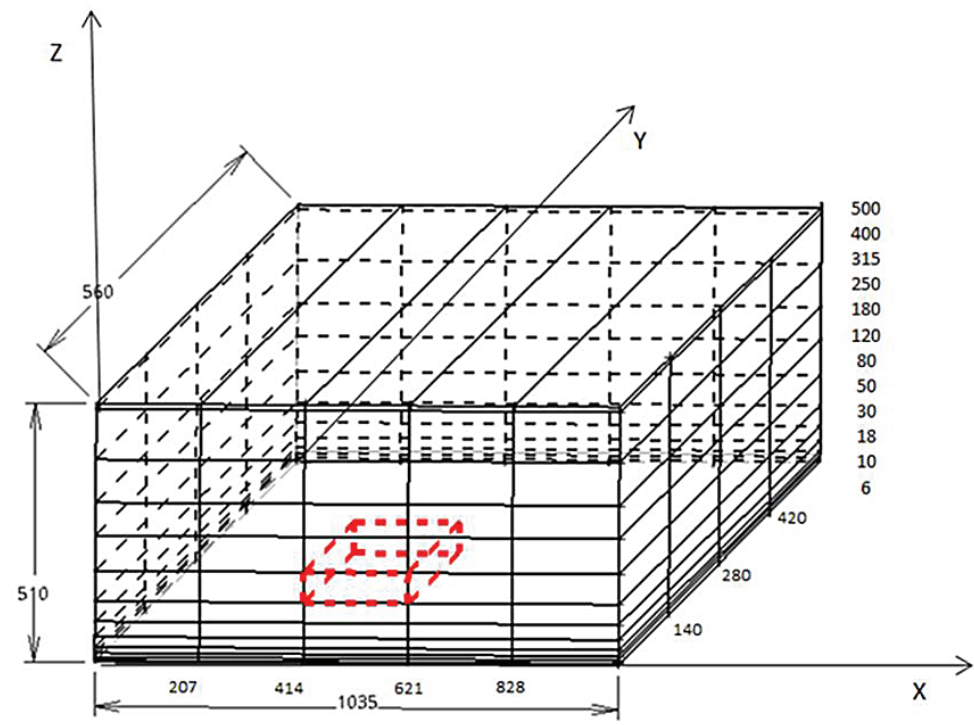

Fig. 4. Diagram of the division of the milling machine working space into working subspaces (red color indicates a single exemplary subspace)

operations are carried out (Fig. 5) in the indicated 8 subspaces of the machine working space.

The knowledge of these subspaces can be used to design a test piece reflecting the machining tasks performed on the milling machine. The specified event frequencies can be used in the evaluation procedures used in the operation-based tests. Normalization was carried out, which consisted in rejecting the results from $14.7 \%$ of the subspaces that were least represented in the analysis and treating the results from the 8 most frequently used subspace of the machine tool as $100 \%$. The results were normalized to obtain the weighting coefficients useful for assessing the

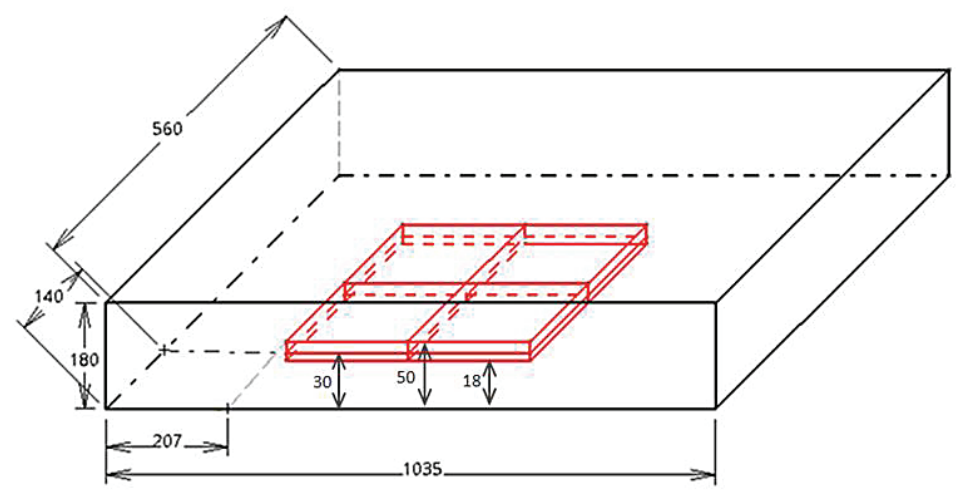

Fig. 5. Diagram of distribution of selected subspaces of the milling machine working spaces, in which machining operations are most likely to occur

Table 2. Normalized weighting factors "w" dependent on dimensional ranges of the coordinate system axes

\begin{tabular}{|c|c|c|c|}
\hline $\begin{array}{c}\text { Dimensional range } \\
\text { on the } z \text { axis }[\mathrm{mm}]\end{array}$ & $\begin{array}{c}\text { Dimensional range } \\
\text { on the } x \text { axis }[\mathrm{mm}]\end{array}$ & $\begin{array}{c}\text { Dimensional range } \\
\text { on the } y \text { axis }[\mathrm{mm}]\end{array}$ & $\begin{array}{c}\text { Normalized weighting } \\
\text { factor " } w \text { " }\end{array}$ \\
\hline $30-50$ & $207-414$ & $140-280$ & 0.253 \\
\hline $30-50$ & $207-414$ & $280-420$ & 0.133 \\
\hline $30-50$ & $414-621$ & $140-280$ & 0.167 \\
\hline $30-50$ & $414-621$ & $280-420$ & 0.118 \\
\hline $18-30$ & $207-414$ & $140-280$ & 0.122 \\
\hline $18-30$ & $207-414$ & $280-420$ & 0.069 \\
\hline $18-30$ & $414-621$ & $140-280$ & 0.081 \\
\hline $18-30$ & $414-621$ & $280-420$ & 0.06 \\
\hline
\end{tabular}



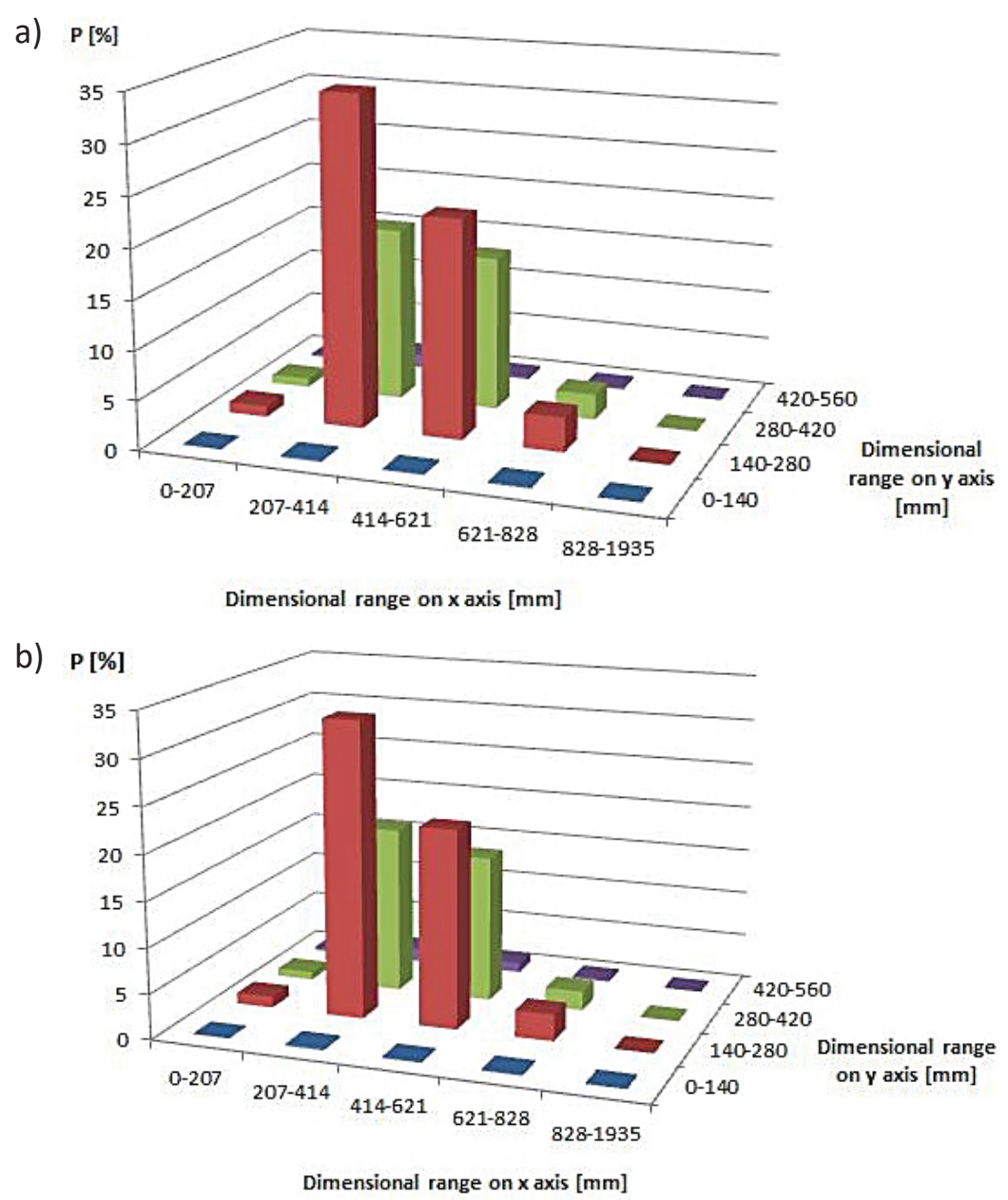

Fig. 6. Distributions of the frequency of occurrence of the cutting force in the milling machine working space in $(x, y)$ coordinates for over 600 machining programs: a) for the range of nominal dimensions $30-50 \mathrm{~mm}$ on the $z$ axis, b) for the range of nominal dimensions $18-30 \mathrm{~mm}$ on the $z$ axis

a)

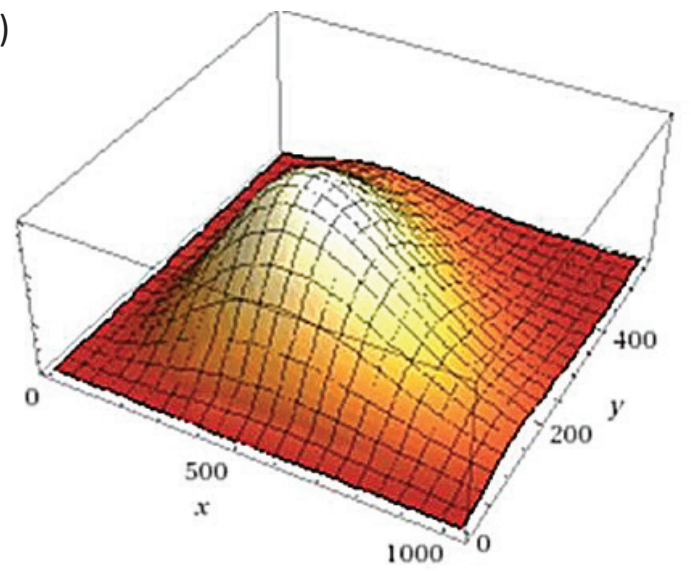

b)

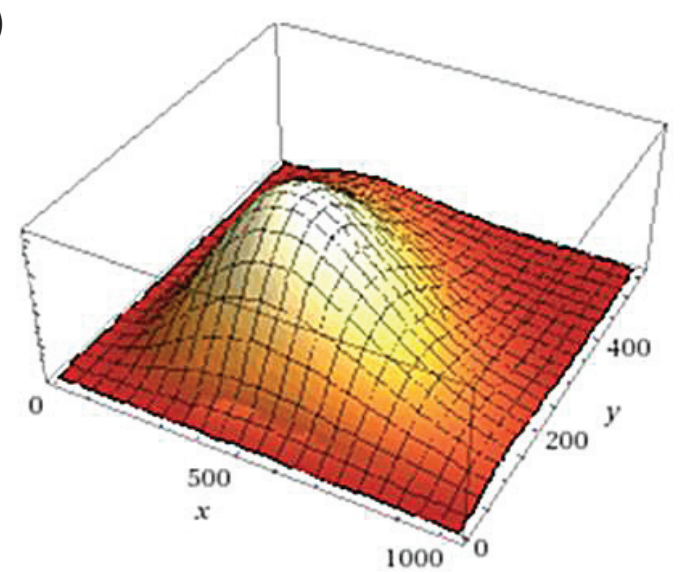

Fig. 7. Two-dimensional beta distributions of the probability of the cutting force in the milling machine working space in $(x, y)$ coordinates for more than 600 machining programs: a) for the range of nominal dimensions $18-30 \mathrm{~mm}$ on the $z$ axis, b) for the range of nominal dimensions $30-50 \mathrm{~mm}$ on the $z$ axis.

properties of a numerically controlled milling machine (Table 2).

Since the highest probabilities of machining events occurred in the two ranges of nominal dimensions, namely $18-30 \mathrm{~mm}$ and $30-50 \mathrm{~mm}$, the corresponding frequency distributions (Fig. 6) were approximated with two-dimensional betasystems, which are presented in Figure 7. 
Both obtained distributions are characterized by the asymmetry of the positions of the cutting tool in the working space of the milling machine. The load distributions are clearly concentrated in a limited area of the working space. This can be used to develop a suitable geometry for the test pieces used in the operation-based tests of these machines and to evaluate the properties of this milling machine based on the machining tests performed.

\section{CONCLUSIONS}

The results presented in this paper show that it is possible to develop the appropriate applications that allow determining the probability of the cutting tool position in the working space of a numerically controlled milling machine based on machining programs. Their application makes it possible to determine the load distribution in the working space of this machine tool, even before machining. Under industrial conditions, this may allow the rapid testing of the milling machine's accuracy to be limited to the areas where machining is expected.

The presented two-dimensional Beta distributions reflect the asymmetrical probability distribution of the cutting tool position in the machine working space. The load distribution in the working space of the numerically controlled milling machine is clearly concentrated in a limited working area. This can be used to develop a method for evaluating the properties of a numerically controlled milling machine based on machining tests. This knowledge can also be used to develop the machine tool acceptance procedures, which are usually agreed between the machine manufacturer and the user. The information on the most common load conditions in a numerically controlled milling machine structure can also be taken into account when creating the numerical model of the machine tool and in the prototype development stage.

The presented results also show that twodimensional Beta distributions can be used to describe the load distribution in the working space of a numerically controlled milling machine, which are a simplification of the threedimensional actual probability distributions, linking them to the limits of nominal dimensions according to the ISO standard. These results also allow obtaining the information about the correct mounting point of the workpiece in order to change the load distribution to one, which allows for a more even distribution of loads in the machine tool working space.

\section{REFERENCES}

1. Skoczyński W. Ocena własności obrabiarek na podstawie dokładności obróbki. Cz. 1. Metody oceny. Przegląd Mechaniczny. 2003;2, 15-24.

2. ISO 10791-7:2014. Test conditions for machining centres - Part 7: Accuracy of finished test pieces.

3. Ibaraki S., Ota Y. A machining test to evaluate geometric errors of five-axis machine tools with its application to thermal deformation test. Procedia CIRP. 2014;14, 323-328.

4. Miko E., Przybytniewski A. Badanie dokładności pracą tokarki CTX ALPHA 500. Mechanik. 2015;89, 460-468.

5. Styp-Rekowski M. Metody diagnozowania obrabiarek na podstawie dokładności obróbki. Zagadnienia Eksploatacji Maszyn. 2006;41(3), 129-141.

6. Jiang Z., Tang X., Zhou X., Zheng S. Machining tests for identification of location errors on five-axis machine tools with a tilting head. International Journal of Advanced Manufacturing and Technology. 2015;79, 245-254.

7. Tseng B.T.L., Kwon Y.J. Characterization of machining quality attributes based on spindle probe, coordinate measuring machine, and surface roughness data. Journal of Computational Design and Engineering. 2014;1(2), 128-139.

8. Weck M., Hanrath G. Fahigkeitsuntersuchungen an Werkzeugmaschinen. Seminar Steigerung der Genauigkeit von Werkzeugmaschinen. Messung - Beurteilung - Optimierung, ADITEC, Aachen, Germany 1995.

9. Ślusarczyk Ł. Budowa konwertera kodu G współpracującego z programami CAD/CAM. Czasopismo Techniczne. Seria: Mechanika. Wydawnictwo Politechniki Krakowskiej. 2011;15, 101-111.

10. Piórkowski P, Skoczyński W. Budowa aplikacji do wyznaczania położenia narzędzia podczas operacji skrawania. Interdyscyplinarność badań naukowych. 2015;1, 213-218.

11. KrzyżanowskiJ.Własnościukładukonstrukcyjnego obrabiarek skrawających. Zagadnienia oceny ze względu na dokładność kształtowania. Prace Naukowe Instytutu Technologii i Budowy Maszyn Politechniki Wrocławskiej, Wrocław 1990.

12. ISO 286-2:2010. Geometrical product specifications (GPS) ISO code system for tolerances on linear sizes Part 2: Tables of standard tolerance classes and limit deviations for holes and shafts. 